\title{
ÜÇ BOYUTLU HAREKET ANALIZINDE SAYISAL FOTOGRAMETRIK YÖNTEMLERIN GERÇEK ZAMANLI OLARAK KULLANILMASI
}

\author{
Mustafa CANIBERK*, Faik Ahmet SESLí2 ${ }^{2}$ Cem ÇETIN ${ }^{3}$ \\ ${ }^{1}$ Harita Genel Komutanlığı, Fotogrametri Dairesi, Ankara, Türkiye \\ ${ }^{2}$ Ondokuz Mayıs Üniversitesi, Mühendislik Fakültesi, Harita Mühendisliği Bölümü, Samsun, Türkiye \\ ${ }^{3}$ Süleyman Demirel Üniversitesi, Tıp Fakültesi Spor Hekimliği ABD, Isparta, Türkiye
}

\begin{tabular}{l} 
Anahtar Kelimeler \\
\hline Hareket Analizi \\
Sayısal Fotogrametri \\
Üç Boyutlu Analiz \\
Biyomekanik
\end{tabular}

Anahtar Kelimeler

Hareket Analizi

Üç Boyutlu Analiz

Biyomekanik

\begin{abstract}
Özet
Fotogrametrik ölçmeler tüm dünya üzerinde çok farklı bilim araştırmalarında kullanılmakta, hassas ve etkili çözümler sunmaktadır. Bu ölçümlerin de kullanımı kolay, kalitesi yüksek ve kısa zamanda olması istenmektedir. Fotogrametrik teknikler fotoğraflardaki veya kamera ile çekilen dijital görüntülerdeki objelerin direk ölçümü (metrik yorumlanması) esasına dayanır. Kamera kalibrasyonu ile kamera parametreleri matematiksel olarak belirlenir. Görüntü koordinatları ve nesne uzay koordinatları $(X, Y, Z)$ arasında analitik bir ilişki modellenir ve dönüşüm (transformasyon) yapılır.

Sporda hareket analizinin doğal ortamda video kameralar ile kaydedilerek fotogrametrik yöntemlerle değerlendirilmesi günümüzde farklı uygulamalarda başarılı olarak gerçekleștirilmiştir. Ancak literatür incelendiğinde sporcu hareketlerinin analizi büroda gerçekleștirilen değerlendirme adımlarından sonra ortaya çıkarılmaktadır.

Sporcunun hareketini tamamlamasının ardından hareketin üç boyutlu ve gerçek zamanlı olarak gösterilebilmesi konusu günümüzde gittikçe önem kazanmaktadır. $\mathrm{Bu}$ çalışmada sporcu hareketlerinin fotogrametrik yöntemlerle gerçek zamanlı olarak belirlenmesi için bir tasarım yapılacaktır.
\end{abstract}

\section{USE OF DIGITAL PHOTOGRAMMETRY FOR REAL TIME 3D MOTION ANALYSIS}

\begin{tabular}{l} 
Keywords \\
\hline Motion Analysis \\
Digital Photogrammetry \\
3D Analysis \\
Biomechanics
\end{tabular}

\begin{abstract}
Photogrammetric measurements are used all over the world for very different scientific researchs also offer precise and effective solutions. These measurements should be easy to use, high quality and provided as soon as possible. Photogrammetry is based on direct measurement of the objects from images (metric interpretation) which is captured with camera or photographs. Camera parameters are determined with camera calibration procedures as mathematically. An analytical relationship modeled between image coordinates and object space coordinates $(\mathrm{X}, \mathrm{Y}, \mathrm{Z})$ and transformations completed.

Conducting the motion analysis in the sports by recording the motions with video cameras in the natural environment and evaluating them through photogrammetric methods has been carried out successfully through different applications today. However, when we examine the literature, the analysis of the athletic motions is revealed following the evaluation phases conducted at the office.

Displaying motion of athletes in three dimensions and in real time as soon as the motion finished increasingly gaining importance. In this study, a design will be made to determine motion of athletes in real time with photogrammetric methods.
\end{abstract}

\footnotetext{
* ilgili yazar/Corresponding author: mustafa.caniberk@hgk.msb.gov.tr, +90-312-595-2290
} 


\section{Giriş}

Fotogrametrik görüntü elde edilmesi ve değerlendirilmesindeki otomasyon ve doğruluk, üç boyutlu cisim koordinatlarının fotoğraflardaki ölçümlerden elde edilmesindeki kolaylık ve sürat artık fotogrametrinin gelişim yönünü belirleyen en önemli etkendir.

Birçok alanda olduğu gibi hareketli objelerin takibinde de stereo-fotogrametrik yöntemler gün geçtikçe artan bir ivmeyle kullanılmaktadır. Hareketli hedefe ait fotogrametrik bilgiler ile elde edilen konumsal veriler farklı sektörel analizlerde kullanılmaktadır. Son yıllarda özellikle gerçek zamanlı video görüntüleri üzerinden yapılan çalışmalarda yüksek hacimli veriler kullanılarak elde edilen konumsal bilgilerle uygulamaların yapıldığı görülmektedir.

Sporcu sağlı̆̆ı ve sporcu gelişimi çalışmalarında sıklıkla üç boyutlu hareket analiz sistemleri kullanılmaktadır. Bilindiği üzere sporcu hareketleri çok kısa bir zaman içerisinde ve hızla gerçekleşmektedir. Anlık hareketlerin yakalanabilmesi için fotogrametrik teknikler kullanılması, fotogrametrinin diğer ölçme yöntemlerine göre en büyük avantajı olan "ölçmelerin cisimle temas kurmadan fotografik izdüşüm üzerinden yapılması” ilkesinin doğal bir sonucudur.

Spor etkinliğine göre vücudun belirli hareket sistemlerinin (kemik, eklem ve kas) kullanıldığı bilinmektedir. İnsanoğlunun yaptığı hareketlerin büyük çoğunluğu bilinçli olarak öğrenildikten sonra bu bilgilerin beyinde otomatikleşmesi ile gerçekleşir. Bununla birlikte bir sporcu grubu içerisinde bütün sporcular aynı eylemi gerçekleştirirken bu grup içerisinden sadece biri en başarılı sayılmaktadır. Başarı kesin bir olgu olduğu için burada başarılı sporcunun yapmış olduğu hareketler önem taşımaktadır. Sportif etkinliklerde yanlıș yönde otomatikleşmiş bir hareketin düzeltilmesi oldukça güçtür. Spor alanında başarılı olmak ve profesyonelleşebilmek için doğru hareketin doğru zamanda yapılması gerekmektedir. Yine sporcularda aşırı yüklenme sonucu belirli bölgedeki eklem ve kasların deforme olması kaçınılmazdır. Bu durum spor yaralanmaları ve sakatlıklarına yol açmaktadır. Bu durumda çalışan ve yük binen eklem ve kasların ortaya çıkarılması gerekir.

Spor biliminde, sporcuların yaptıkları her türlü hareketi ortaya koymak için birçok çalışma gerçekleştirilmiştir. Özellikle eklem ve kasların biyomekanik (Smith, 1973; Laubach, 1976; Buff vd., 1988; Bell vd., 1990; Markolf vd., 1995) ve anatomik
(Hida, 1994; Bendijaballah vd., 1997) analizleri yapılmıştır.

Son yıllarda teknolojinin ilerlemesine paralel olarak sayısal fotogrametrik yöntemlerle görüntü analizlerinin 3 boyutlu olarak gerçekleştirilmesi, birçok vücut hareketinin değerlendirilmesine yeni bir boyut kazandırmıștır (Ambrosio vd., 2001; Awan vd., 2002; Pers vd., 2002; Cerveri vd., 2003; Krosshaug ve Bahr, 2005; Tsuruoka vd., 2005). Bu literatür ışığında gerçekleştirilen medikal çalışmalar, sporcuların karşılaşabilecekleri birçok patolojik predispoze (yatkınlık) faktörlerin teşhis ve tedavisinde fotogrametrik yöntemlerin geçerliliğini doğrulamaktadır (RamseyveWretenberg, 1999; Kapteinvd., 2004; Wong vd.,2005 ).

Fotogrametrik değerlendirmeye esas olmak üzere incelenen objelerin fotoğraf çekimleri sırasında bilinen bir koordinat sistemi içerisinde tanımlanması veya obje üzerinde bazı noktalara koordinat verilmesi gerekmektedir. Obje üzerindeki noktaların 3 boyutlu koordinatlarının geleneksel yöntemlerle ölçülmesinin hemen hemen olanaksız olması nedeniyle otomatik ölçüm yapabilen bir sistem tasarlanmıştır.

\section{Problemin Tanımı ve Çalışmanın Amacı}

İnsan doğada var olan mükemmel sistemlerin bașında gelmektedir. Bu mükemmeliyet insanın hareketine de yansımıştır. İnsan hareketi tarihin en eski dönemlerinden beri araştırmacıların ilgisini çekmiştir. 1830'larda Weber kardeşlerin öncülüğünde modern anlamda yürüyüş analizi çalışmaları başlamıştır (Yavuzer, 2007). Günümüzün araştırmalarına Winter tarafından gerçekleştirilen çalışmalar öncülük etmektedir (Winter, 1990).

Tüm fotogrametrik veri toplama sistemleri elde edilmek istenen verileri 2 boyutlu (2B) alıcı yardımıyla kaydederler. Ancak insan hareketi genelde bir düzlem yerine 3 boyutlu (3B) bir uzayda gerçekleşir. Hareket analizi için gerekli olan 3B uzaysal konum bilgisini elde edebilmek için ilgilenilen hareketin en az eşzamanlı 2 farklı görüntüsüne gereksinim vardır.

Ülkemizde sporcu hareketlerinin fotogrametrik yöntemlerle analiz edildiği çalışmalar incelendiğinde, görüntülerin alınması (ölçülerin yapılması) ve analizlerin yapılması süreçlerinin birbirinden farklı zamanlarda gerçekleştirildiği görülmektedir. Yani fotogrametrik çalışmalar büroda gerçekleştirilmektedir. Bu durum sporcu eğitimi için uygun bir ortam oluşturmamaktadır. Bu açıdan bakıldığında konumsal verilerin gerçek zamanlı olarak belirlenmesi önem arz etmektedir. 
Sporcu hareketini tamamladı̆̆ı anda konumsal verilerin ortaya çıarması ile sporcunun hareketindeki eksiklikler/yanlışlıklar ortaya çıkarılacak ve eğitim verimliliği artacaktır.

Bu çalışma sonucunda hareket analiz sistemlerinin konumsal veri ihtiyacının fotogrametrik yöntemlerle belirlenen konumsal veriler ile karşılanması hedeflenmektedir. Konumsal verilerin belirlenmesi, ölçüm sonrası veri işleme çalışmaları olmaksızın gerçek zamanlı olarak gerçekleştirilecek ve böylelikle zaman tasarrufu sağlanarak etkinlik artırılmış olacaktır.

\section{Sayısal Fotogrametri}

Sayısal Fotogrametri, sayısal görüntülerin kullanıldığı fotogrametri alanıdır. Sayısal fotogrametride fotogrametrinin matematik modeli aynen kullanılmaktadır. Yalnızca sayısal görüntü işlerken bazı ek parametrelere ihtiyaç vardır. Fotogrametrinin matematik modeli aşağıda belirtilen doğrusallık denklemi ile ifade edilir.

$\xi=\xi_{0}-c \frac{r_{11}\left(X-X_{0}\right)+r_{21}\left(Y-Y_{0}\right)+r_{31}\left(Z-Z_{0}\right)}{r_{13}\left(X-X_{0}\right)+r_{23}\left(Y-Y_{0}\right)+r_{33}\left(Z-Z_{0}\right)}$

$\eta=\eta_{0}-c \frac{r_{12}\left(X-X_{0}\right)+r_{22}\left(Y-Y_{0}\right)+r_{32}\left(Z-Z_{0}\right)}{r_{13}\left(X-X_{0}\right)+r_{23}\left(Y-Y_{0}\right)+r_{33}\left(Z-Z_{0}\right)}$

$\mathrm{Bu}$ formüllerde; $\xi, \eta$ iki boyutlu fotoğraf koordinatları $\mathrm{x}, \mathrm{y}, \mathrm{z}$ üç boyutlu model koordinatları, X, Y, Z üç boyutlu kartezyen koordinat sistemindeki koordinatlardır.

$\xi_{0}, \eta_{0} \mathrm{r}$ fotoğraf ana noktası H'nin fotoğraf koordinatları, c fotoğraf çekme makinesinin sabiti, $\mathrm{X}_{0}, \mathrm{Y}_{0}, \mathrm{Z}_{0}$ fotoğraf çekme merkezinin fotoğraf koordinatları, $\omega, \varphi, \kappa: \mathrm{R}$ dönme matrisinin üç dönme açısıdır.

İç yöneltme $\left(\xi_{0}, \eta_{0}, c\right)$ ve diş yöneltme $\left(\mathrm{X}_{0}, \mathrm{Y}_{0}, \mathrm{Z}_{0}, \omega, \varphi, \kappa\right) \quad$ elemanlarl merkezi izdüşürülmüş fotoğrafi tanımlarlar.

Sayısal fotoğraf $g_{i j}$ elemanları ile (iki boyutlu) bir G matrisinden oluşur. Şekil 1'de satır indeksi i birer aralıklarla I den I ya gider, yani i=I(I) I. sütun için ise karşılık gelen indeksleme ise j= I(I)J dir. Bir fotoğraf elemanın büyüklüğü $\Delta \xi, \Delta \eta$ dir. Bir sayısal fotoğrafta piksel konumu ile $\xi, \eta$ koordinat sistemi arasındaki bağıntı gereklidir. Şekil 1'de bir fotoğraf koordinat sistemi yerleştirilmiştir (Kraus, 2006)

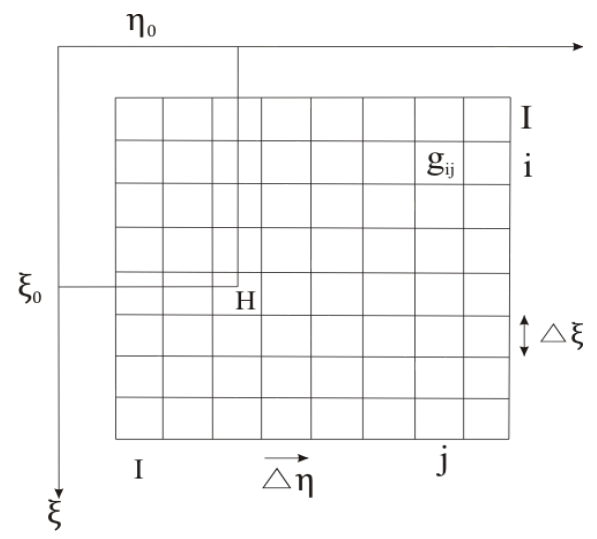

Şekil 1.Sayısal fotoğraf matrisi

\section{Materyal Ve Yöntem}

Sistemin temel donanımı Optitrack firmasının V120 Duo model streo kamerasıdır. Bu kamera, 800 nm infrared filtresi, farklı görüntüleme modları ile küçük alanlarda 6Dof takip ve izleme yeteneğine sahiptir. Kameranın genel görünümü Şekil2'de, sunulmuştur.

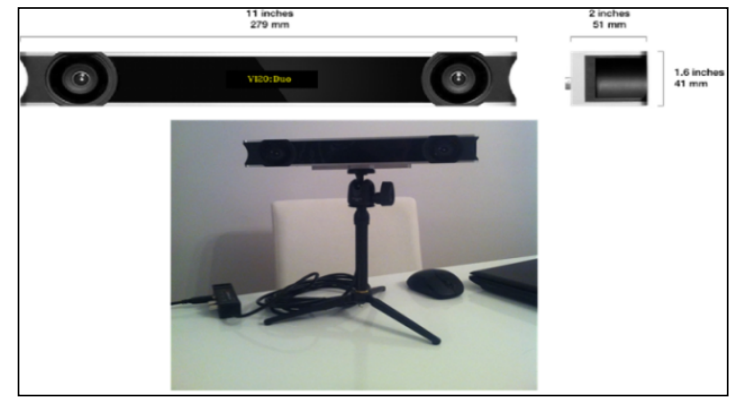

Şekil 2. V120 Duo kamera genel görünüşü

Kamera ile 640x480 çözünürlüğünde görüntü alınabilmektedir. Maksimum frame rate $120 \mathrm{fps}$ olarak bildirilmiştir. Kamera ile "Object", "Segment", "Precision", "Grayscale”, "MJPEG Grayscale” ve "Raw Grayscale” özellikleri ile görüntü alınabilmektedir. Her iki kameranında etrafında 26 adet $850 \mathrm{~nm}$ IR led bulunmaktadır. Aynı zamanda her iki kamerada dâhili $800 \mathrm{~nm}$ IR pass filtre mevcuttur.

Kamera ile elde edilecek görüntülerde IR filtre kullanıldığında, yansıtıcı işaretçiler obje yakalama algoritmalarında güzel sonuçlar vermektedir. $\mathrm{Bu}$ açıdan değerlendirildiğinde hareket yakalama uygulamalarında vücudun belirgin noktalarına yerleştirilecek yansıtıcı işaretler ile kusursuz biçimde hareket yakalanabilmektedir. Bu çalışmada koordinatları belirlenecek 4 adet yansitıcı işaretçinin bulunduğu bir obje seçilmiş ve yansitıcı işaretçilerin koordinatları belirlenmiştir (Şekil 3). 


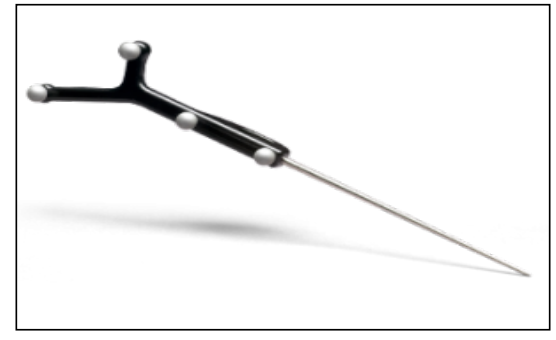

Şekil 3.Çalışmada kullanılan yansıtıcı işaretçilerin bulunduğu obje

Her iki kamera görüntüsü içerisine giren yansıtıcı işaretçilerin fotoğraf koordinatlarını kullanarak bu işaretçilerin ölçüm uzayında tanımlanan uzay koordinat sistemindeki 3B koordinatlarının hesaplanması için 3B benzerlik dönüşümü kullanılacaktır. Söz konusu benzerlik dönüşümünün yapılabilmesi için öncelikle her iki kameranın uzay koordinat sistemindeki öteleme ve dönüklük parametrelerinin (dış yöneltme parametrelerinin) dengeleme yapılarak hesaplanması gerekmektedir.

$\mathrm{Bu}$ dengelemenin yapılabilmesi için ise uzay koordinat sistemindeki 3B koordinatları (X, Y, Z) hassas olarak bilinen en az dört adet sabit referans noktasına ihtiyaç duyulmaktadır. $\mathrm{Bu}$ ihtiyacı karşılamak için en az dört köşesinde yansıtıcı işaretçiler bulunan bir referans yüzey kullanılmıștır. Şekil 4'de gösterilen bu düzlem ölçümler başlamadan önce sabitlenecek ve düzlem üzerindeki bir numaralı yansıtıcı işaretçi $(0,0,0)$ noktasını oluşturacak şekilde uzay koordinat sistemi bu düzlem üzerinde tanımlanacaktır.

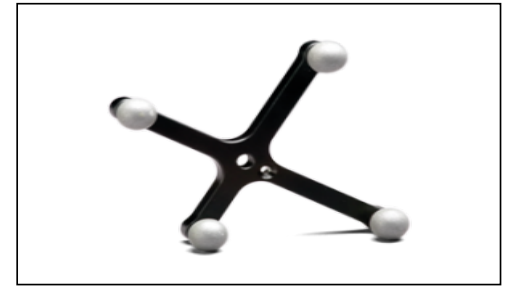

Şekil 4. Çalışmada kullanılan referans yüzeyi

\section{Yapılan Çalışmalar}

Kamera ile birlikte gelen SDK kütüphaneleri incelenmiş ve bu kütüphaneler kullanılarak stereo görüntü alabilen uygulama geliştirilmiştir. Böylelikle Optitrack V120 kamera donanım kilidi olmaksızın her bilgisayarda kullanılabilecektir (Şekil 5).

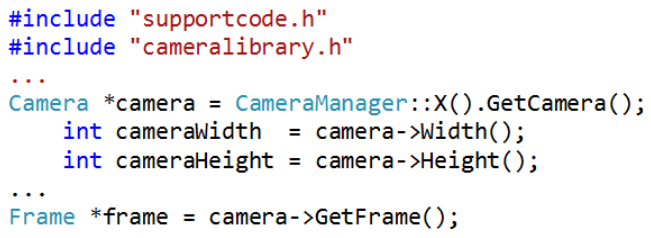

Şekil 5. Kamera bağlantı programı kod örneği

Kameranın "Precision" ve "Segment" olarak adlandırılan görüntüleme modlarında çalışmalar yapılmıştır. Yapılan çalışmalar neticesinde şekiller (marker) otomatik olarak yakalanmıştır. Test amaçlı 4 (dört) adet marker takılı bir işaretçi kullanılmıştır. "Precision" ve "Segment" modlarda 4 marker da yakalanmıştır. Çalışma ile ilgili görüntüler Şekil 6'da sunulmuştur.

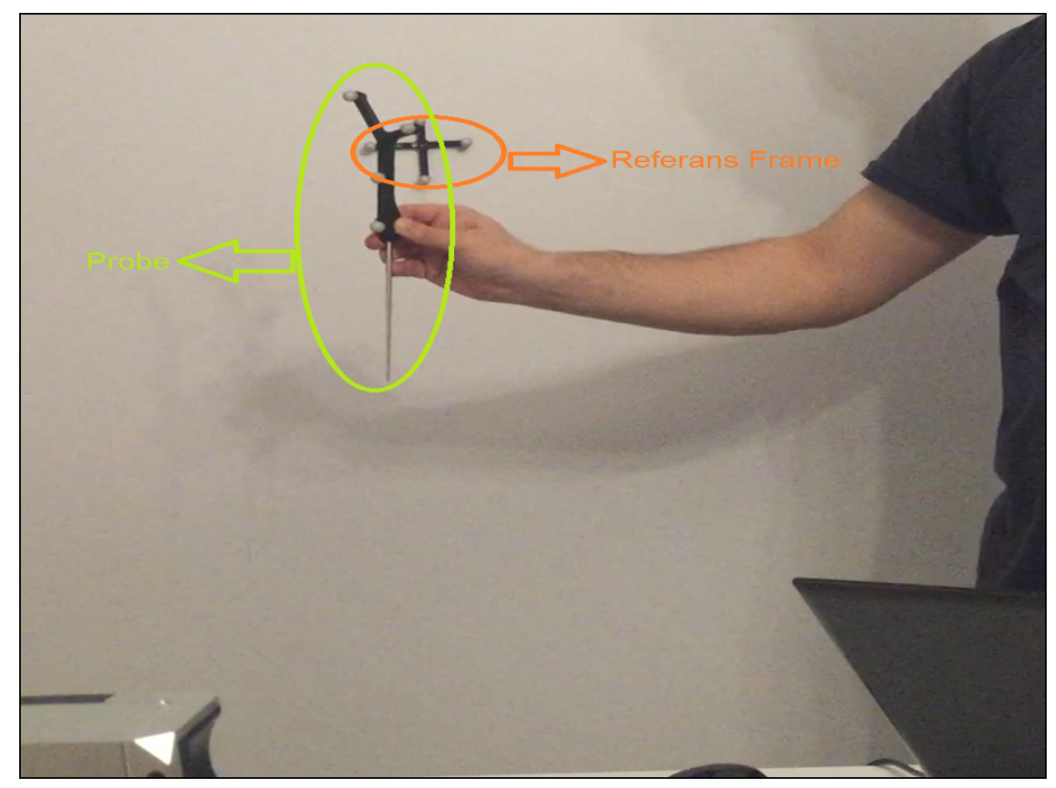

Şekil 6. Optitrack V120 kamera ile gerçekleştirilen çalışma görüntüsü 
Sistemin test çalışmalarında olumlu sonuçlar alınamaması durumunda yani V120 kameranın planlanan ölçüm alanında yeterli doğrulukta ölçü yapamaması durumunda birden fazla kamera ile ölçüm yapılmasına olanak sağlayan OptiHub cihazı kullanılarak çalışmalar yapılacaktır. Bu kapsamda Şekil 7'de sunulan OptiHub cihazı ve V100 model kameralar ile test çalışması gerçekleştirilmiştir.

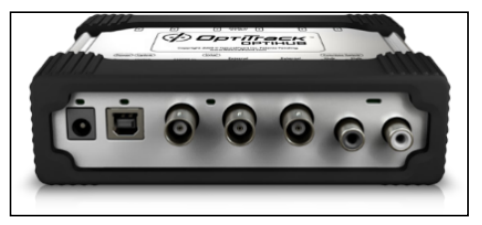

Şekil 7. Optitrack OptiHub cihazının görünümü

Gerçekleştirilen çalışmada kullanılan kod örneği Şekil 8'de sunulmuştur. Bu cihaz ile 6 adet kamera aynı anda kullanılabilmektedir. OptiHub ile birden fazla kamera sisteme bağlanabilir ve senkronlu olarak görüntü aktarılabilir. SDK kütüphaneleri kullanılarak geliștirilen program ile OptiHub donanım kilidi olmadan her bilgisayarda kullanılabilmektedir.

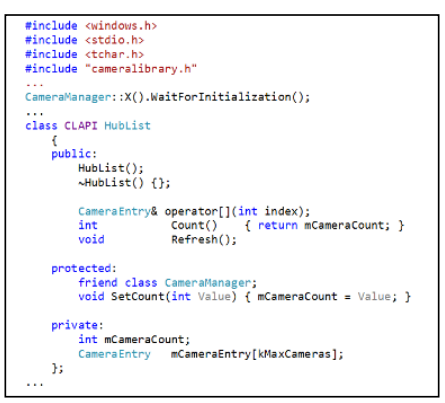

Şekil 8. Optitrack OptiHub cihazı kamera bağlantısı kod örneği
Kameralardan gelen her frame önce senkronlanır. Senkronlaması hatasız olarak yapılan her frame çiftinde yakalanan objelerin koordinatları yazdırılır. Video görüntüsünden saniyede 120-90-60 vb. sayılarda frame alınabilir. Buradaki uygulamada her 100 frame'den birisi alınarak senkronlama yapılmıştır.

Takip algoritması ile örnek uygulama gerçekleştirilmiş ve alınan sonuçlar bir dosyaya yazdırılmıştır. Bu çalışmada kullanılan 4 marker'dan oluşan bir işaretçi ve 4 marker'dan oluşan bir referans frame ait toplam 8 objenin fotoğraf koordinatları iki kamera için de ayrı ayrı yakalanmıştır. Şekil 9'da uygulama kod örneği, Tablo1-2'de gerçek zamanlı olarak elde edilen fotoğraf koordinatları görülmektedir.

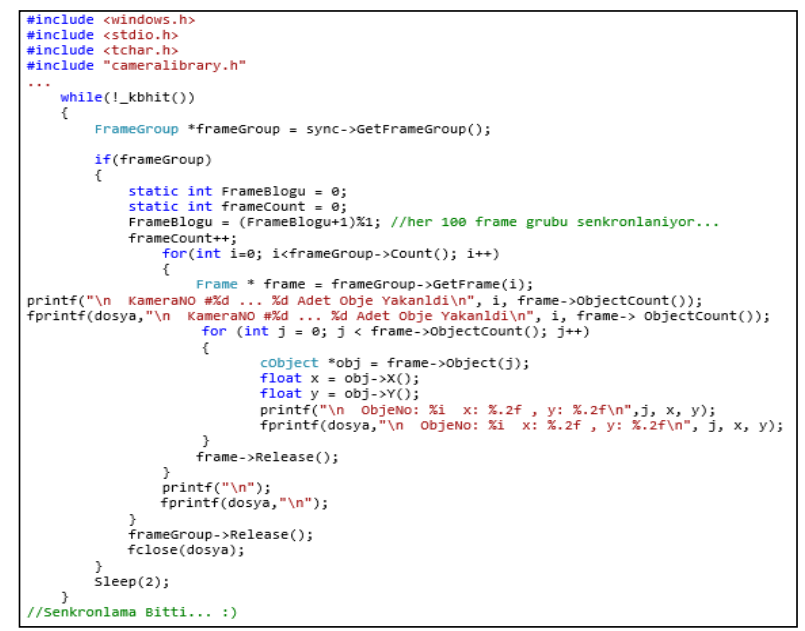

Şekil 9. Optitrack V120 kamera ile objelerin fotoğraf koordinatlarını alan uygulama kod örneği

Tablo 1. Referans yüzeyine ait gerçek zamanlı belirlenen fotoğraf koordinatları

\begin{tabular}{|c|c|c|c|c|c|}
\hline \multicolumn{3}{|c|}{ Kamera No:1 } & \multicolumn{3}{|c|}{ Kamera No: 2} \\
\hline Obje No & $\mathrm{x}$ & $\mathrm{y}$ & Obje No & $\mathrm{x}$ & $\mathrm{y}$ \\
\hline Ref1 & $-0,1503$ & $-0,2742$ & Ref1 & $-0,6104$ & $-0,3253$ \\
\hline Ref2 & 0,4895 & $-0,2835$ & Ref2 & 0,0248 & $-0,3455$ \\
\hline Ref3 & $-0,1363$ & 0,3532 & Ref3 & $-0,5686$ & 0,2928 \\
\hline Ref4 & 0,4834 & 0,3377 & Ref4 & 0,0480 & 0,2789 \\
\hline \multicolumn{3}{|c|}{ Projeksiyon Merkezi Koor. } & \multicolumn{3}{|c|}{ Projeksiyon Merkezi Koor. } \\
\hline $\mathrm{x}_{0}$ & yo & $\mathrm{z}_{0}$ & $\mathrm{x}_{0}$ & $\mathrm{y}_{0}$ & $\mathrm{Z}_{0}$ \\
\hline$-0,0411$ & $-0,1564$ & 1,3950 & 0,2893 & $-0,1668$ & 1,3892 \\
\hline \multicolumn{3}{|c|}{ Üç Eksendeki Dönüklükler } & \multicolumn{3}{|c|}{ Üç Eksendeki Dönüklükler } \\
\hline$\omega$ & $\varphi$ & $\kappa$ & $\omega$ & $\varphi$ & $\kappa$ \\
\hline 0,1668 & $-0,0579$ & 0,0205 & 0,1885 & 0,0847 & 0,0262 \\
\hline
\end{tabular}


Tablo 2. İşaretçilere ait gerçek zamanlı belirlenen fotoğraf koordinatları

\begin{tabular}{|l|c|c|l|c|c|}
\hline \multicolumn{3}{|c|}{ Kamera No:1 } & \multicolumn{3}{c|}{ Kamera No:2 } \\
\hline Obje No & $\mathrm{x}$ & $\mathrm{y}$ & Obje No & $\mathrm{x}$ & $\mathrm{y}$ \\
\hline Marker1 & 0,5143 & 1,0364 & Marker1 & 0,1720 & 0,9806 \\
\hline Marker2 & 0,7390 & 1,2610 & Marker2 & 0,4322 & 1,2130 \\
\hline Marker3 & 0,8954 & 1,4237 & Marker3 & 0,6135 & 1,3803 \\
\hline Marker4 & 0,5624 & 1,4377 & Marker4 & 0,3036 & 1,3850 \\
\hline
\end{tabular}

İşaretçilerin hareketini takip edebilmek için ise fotoğraf koordinatları ve dış yöneltme parametreleri kullanılmış ve uzaysal benzerlik dönüșümü (eş doğrusallık-kolinearite) bağıntıları kullanılarak çözüme gidilmiştir. Çözüm sonucunda elde edilen uzay koordinatları Tablo 3'de sunulmuştur.

Tablo 3. İşaretçilere ait gerçek zamanlı belirlenen uzay koordinatları

\begin{tabular}{|l|c|c|c|}
\hline Obje No & $\mathbf{x}$ & $\mathbf{y}$ & $\mathbf{z}$ \\
\hline Marker1 & 0,2030 & 0,4242 & $-0,0793$ \\
\hline Marker2 & 0,2816 & 0,5154 & $-0,1099$ \\
\hline Marker3 & 0,3386 & 0,5827 & $-0,1295$ \\
\hline Marker4 & 0,2365 & 0,6070 & $-0,1773$ \\
\hline
\end{tabular}

Söz konusu yansıtıcı işaretçilere ait uzay koordinatlarının yüksek doğrulukta hesaplanması için sağ ve sol görüntülerin dış yöneltme parametrelerin de yüksek doğrulukta belirlenmesi gerekmektedir. $\mathrm{Bu}$ parametrelerin yüksek doğrulukta belirlenmesi için ise merkezi izdüşüm geometrisinin sağlıklı bir şekilde kurulması gerekmekte, bu geometrinin sağlıklı bir şekilde kurulması ise laboratuvar ortamında yapılacak olan iç yöneltme elemanları kalibrasyonuna bağlıdır. Bu kalibrasyon; her iki kameraya ait odak uzaklıklarının, bir pikselin fiziksel boyutlarının, asal nokta fotoğraf koordinatlarının ve çapsal distorsiyon eğrilerinin hesaplanmasını içermektedir. Gerçekleştirilen çalışmada kullanılan Optitrack V120 Duo kamera fabrika çıkıșı olarak kalibre edilmiş bir cihaz olduğu için tekrar kalibrasyon yapılmamıştır.

Çalışmanın tamamını özetleyecek bir görsel Şekil 10'da sunulmuştur. Bu görselde de görüleceği üzere iki kameradan oluşan bir streo görüntüleme sisteminden alınan fotoğraf çiftlerinin her birinde referans yüzeyi ve hareketli objelerin görünmesi gerekmektedir. $\mathrm{Bu}$ görüntü çiftlerinin izdüşüm merkezinin koordinatları ve üç eksendeki dönüklükleri de kullanılarak oluşturulan benzerlik dönüşümüm denklemi ile hedef objelerin üç boyutlu uzay koordinatları hesaplanabilmektedir.

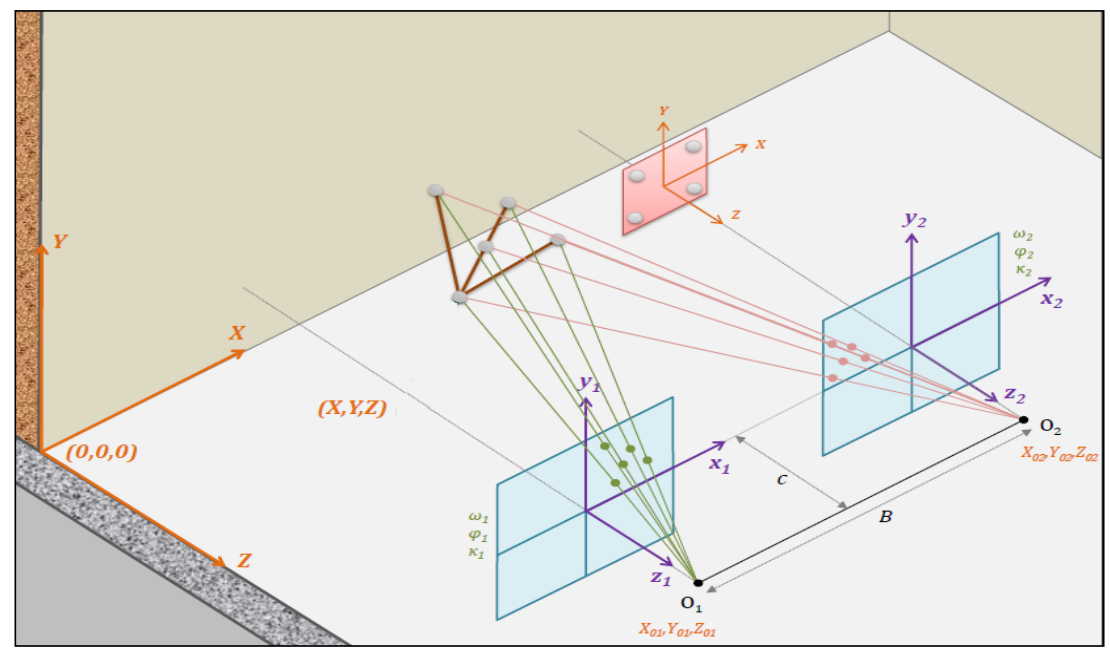

Şekil 10. Çalışmanın özet görüntüsü 


\section{Sonuçlar}

Sporcu hareketlerinin incelenerek analizinin yapılması konusu birçok araștırmacının ilgisinin yoğunlaștığı bir çalışma alanıdır. Özellikle ülkemizde bu tarz analizlerin yapıldığı çalışmalar paket programlar kullanılarak gerçekleștirilmektedir.

Gerçekleștirilen bu çalışma ile hareketli objelerin üç boyutlu uzay koordinatları gerçek zamanlı olarak belirlenmiştir. $\mathrm{Bu}$ açıdan çalışmanın hareket analiz sistemlerinin girdi olarak kullandığ verilerin elde edilmesinde kullanılabileceği değerlendirilmektedir.

Uzay koordinatlarının büro çalışmalarına gerek kalmadan gerçek zamanlı olarak belirlenmesi çalışmaya özgünlük katmaktadır. Böylelikle konumsal verilerin kullanıldığı hareket analizlerinin etkinliği artırılacaktır. Aynı zamanda yazılımda tamamen açık kaynak kodlu bilgisayarlı görme kütüphanelerinin kullanılması gelişecek yeni isteklere etkin biçimde cevap verilmesini sağlayacaktır.

Konumsal verilerin bir raporlama fonksiyonu ile kullanıcılara sunulması durumunda, eğiticilerin veri takibi ve analiz yapabilmelerine olanak sağlanacaktır. Raporlama modülü kullanıcıya araştırdığı antropometrik noktaların uzaysal konum bileşenlerinin zamana göre değişim grafiklerini vererek gerekli analizlerin yapılmasına olanak sağlayacaktır.

Sonuç olarak önerilen konum belirleme altyapısını kullanarak geliștirilecek bir gerçek zamanlı hareket analiz yazılımı; akademisyenlerin, kinematik analizleri inceleyen biyomekanikçilerin, mühendislerin, hekimlerin, fizyoterapistlerin ve spor bilimcilerin çalışmalarında kullanabileceği kolay kullanım özelliği olan bir yazılım olacaktır. Ayrıca bu yazılım sporcuların tekniklerinin incelenmesi ve geliștirmesinde antrenörler tarafından da kullanılabilecektir.

\section{Cıkar Catışması / Conflict of Interest}

Yazarlar tarafından herhangi bir çıkar çatışması beyan edilmemiştir.

No conflict of interest was declared by the authors.

\section{Kaynaklar}

Ambrosio, J., Lopes, G., Costa, J., and Abrantes, J., 2001. Spatial Reconstruction of the Human Motion Based on Images of a Single Camera. J. Biomech., 34: 1217-1221

Awan, R., Smith, J., and Boon, A. J. 2002. Measuring Shoulder Internal Rotation Range of Motion:A Comparison of 3 Techniques. Arch Phys Med Rehabil. 83: 1229-1234.
Bell, A. L., Pederson, D. R., Brand, D., 1990. A Comparison of the Accuracy of Several Different Hip Center Location Prediction Methods. J. Biomech., 23: 617-621.

Bendijaballah, M. Z., Shirazi,-Adl, A., Zukor, D. J., 1997. Finite Element Analysis of Human Knee Joint in Valgus-Varus.Clin. Biomech., 12: 139-148.

Buff, H. U., Jones, L. C., Hungerford, D. S., 1988. Experimental Determination of Forces Transmitted Through the Patello-Femoral Joint. J Biomech. 21:17-23.

Cerveri, P., Pedotti, A., Ferrigno, G., 2003. Robust Recovery of Human Motion from Video Using Kalman Filters and Virtual Humans. Human Mov. Sci., 22: 377-404.

Hida, S., 1994. The Collateral Ligaments of the Elbow Joint: Their Functional Anatomy with Special Reference to the Pathology and Treatment of Post-Traumatic Stiff Elbow.Nipp. Seik. Gakk. Zass. 864-877.

Kaptein, B.L., Valstar, E.R., Stoel, B.C.,Rozing, P.M., and Reiber, J.H., 2004. Evaluation of Three Pose Estimation Algorithms for Model-Based Roentgen Stereophotogrammetric Analysis. Institution of Mechanical Engineers Part H 218, 231-238.

Kraus K., 2006. Photogrammetry. Vol. 1. Nobel Dağıtım. Ankara.

Krosshaug, T., Bahr, R., 2005. A Model-Based ImageMatching Technique for Three-Dimensional Reconstruction of Human Motion from Uncalibrated Video Sequences. J. Biomech. 38: 919-929.

Laubach, L.L., 1976. Comparative Muscular Strength of Men and Women: A Review of the Literature.Aviat Space Environ. Med. 47:534-542.

Markolf, K. L., Burchfield, D. M., Shapiro, M. M., Shepard, M. F., Finerman, G. A., and Slauterbeck, J. L. 1995. Combined Knee Loading States That Generate High Anterior Cruciate Ligament Forces. J. Orth. Res. 13: 930-935.

Pers, J., Bon, M., Kovacic, S., Sibilo, M., and Dezman, B. 2002. Observation and analysis of Large-Scale Human Motion. Human Mov. Sci., 21: 295-311. 
Ramsey, D.K., Wretenberg, P.F. 1999. Biomechanics of the Knee: Methodological Considerations in the in Vivo Kinematic Analysis of the Tibiofemoral and Patellofemoral Joint. Clinical Biomechanics. 14, 595-611.

Smith, J. G., 1973. Biomechanical Analysis of Knee Flexion and Extension. J. Biomech. 6: 79-92.

Tsuruoka, Y., Tamura, Y., Shibasaki, R., and Tsuruoka, M., 2005. Analysis of Walking Improvement with Dynamic Shoe Insoles, Using Two Accelerometers. Physica A. 352: 645-658.

Winter, D. A., 1990.Biomechanics and Motor Control Of Human Movement. 2nd Edition. John Wiley \& Sons. Canada.

Wong Y., Kim W., Ying N., 2005.Passive Motion Characteristics of the Talocrural and The Subtalar Joint Bydual Euler Angles. Journal of Biomechanics 38, 2480-2485.

Yavuzer, G. 2007. The Use of Computerized Gait Analysis in the Assessment of Neuromusculoskeletal Disorders.Journal of Physical Medicine And Rehabilitation Sciences. 10, 2, 043-045. 